\title{
UNA INVESTIGACIÓN SIN MEMORIA PARA UN CINE EN PERMANENTE RENACIMIENTO

\author{
Un vistazo a la investigación sobre cine en Colombia
}

Jerónimo León Rivera Betancur (Universidad de La Sabana)

http://dx.doi.org/10.12795/AdMIRA.2009.01.11

\begin{abstract}
La historia del cine colombiano es la historia del esfuerzo de personas interesadas en el tema que a través de los años han realizado producciones de irregular calidad, la mayor parte de las veces de manera particular y sin mucho apoyo de la empresa privada y el Estado. La investigación sobre el cine colombiano tiene mucha relación con esta tradición, pues aunque se han incrementado los apoyos a esta actividad, aun sigue siendo incipiente y los proyectos que se realizan a menudo ignoran los resultados de proyectos similares realizados dentro y fuera del país. En la investigación sobre cine colombiano, como en el cine nacional mismo, es poco lo que se ha hecho, pero mucho más de lo que la mayoría piensa.
\end{abstract}

PALABRAS CLAVE. Historia del cine, cine, archivos cinematográficos, película, industria cinematográfica, investigación cultural, cinematografía, cine colombiano.

\section{Breve reseña de la producción audiovisual en Colombia}

La investigación sobre el cine colombiano tiene grandes similitudes con la producción cinematográfica del país. Ambas están marcadas por el desconocimiento general de procesos anteriores, ambas son incipientes pero más representativas de lo que el público en general conoce y ambas minimizan su impacto al estar fragmentadas e incomunicadas.

El cine nacional ha estado siempre sujeto al vaivén de la política cultural del Estado que ha pasado de apoyar poco a la industria cinematográfica a no apoyarla y de nuevo dar algunos apoyos. El fomento a la cinematografía siempre ha sido insuficiente, aunque hay que reconocer que en los últimos años esta situación ha mejorado un poco gracias a la ley 814 de 2003 o ley del cine que, por primera vez, regula y fomenta la actividad cinematográfica en el país.

El público y el cine en Colombia han vivido un matrimonio conflictivo lleno de encuentros y desencuentros, de mutua conveniencia y de quejas permanentes de los espectadores frente a la relación cine- realidad y cine- violencia que se da en la cinematografía colombiana; lo que ha llevado a que en muchas ocasiones el público no logre conectarse del todo con las historias que el cine nacional le presenta.

En la primera mitad del siglo XX, el cine colombiano bebió de las fuentes de la literatura hecha en el país, lo que le dio un carácter muy similar al de las características más relevantes de la producción escrita colombiana: bucólica, local, romántica y con altas dosis de nostalgia hacia el campo (sobre todo en la transición entre el país rural y el país urbano originada por los éxodos de los años 50). Esta característica puede verse claramente reflejadas en obras literarias como María, obra emblemática de Jorge Isaacs, que en 1922 se constituyó en la primera película del cine colombiano, dirigida por Máximo Calvo. En los primeros años aparecen películas que reivindican también lo 
campesino, tales como Alma Provinciana (Félix Rodríguez 1925), Allá en el trapiche (Roberto Saa 1943), y Flores del valle (Máximo Calvo 1941). Lastimosamente para el registro histórico de la historia del cine en Colombia, muchas de las primeras películas se perdieron o deterioraron en archivos familiares o personales y hoy no se conserva ninguna copia de las mismas; debido a la falta de políticas estatales de archivo y conservación documental que sólo tomaron forma en 1986.

Entre los primeros años y la década de 1940, el cine colombiano se dedicó a diseñar una imagen idealizada del país por medio de un cine nostálgico de los valores del campo, costumbrista y folclórico. Sólo 13 películas de largometraje fueron realizadas entre 1922 (año del primer largometraje) y 1940.

La década de 1950 sólo dejó cinco largometrajes, ninguno de ellos clave ni representativo para la historia del cine nacional y sólo es hasta 1965 que se presenta el primer hito en la filmografía nacional con la exhibición de la película EI Rio de las tumbas (Julio Luzardo, 1965), un film político de buena factura y narrativa. Esta película antecedió otro gran largometraje de 1967, Pasado el meridiano (José María Arzuaga, 1967), que a juicio de muchos críticos marca un punto fundamental para la historia del cine colombiano

En las décadas del 60 y el 70 fue evidente la influencia de movimientos internacionales como el Neorrealismo Italiano, la Nueva Ola Francesa y El Cinema Novo Brasileño en la cinematografía nacional. Un cine militante y comprometido, con influencia política marxista y una gran tendencia al documental trajo consigo una nueva camada de jóvenes directores de cine educados en el exterior, que llevaron a la gran pantalla historias de denuncia, inspiradas en el conflicto interno colombiano y en las desigualdades sociales.

Los años ochenta en el cine colombiano fueron la manifestación de la necesidad de construir una industria cinematográfica nacional, aun por encima de la estética y el repudio de un amplio sector de la crítica. Algunas cuantas buenas películas tuvieron que compartir espacio con una gran cantidad de películas del mal llamado "cine popular" que buscaba llegar al gran público con productos ligeros en el límite entre lo divertido y lo grotesco, cuya principal función era construir un cine colombiano masivo, mediante una narrativa sencilla y de baja factura técnica. En definitivas, un cine barato que alcanzara buenos rendimientos. A esta situación se suma el hecho de que el cine colombiano del período fue altamente influenciado por series de películas mexicanas de gran impacto comercial en América Latina como las de Sor Tequila, Capulina y La India María; construyendo un fenómeno que generó historias similares en Argentina y Brasil (pornochanchada). La gran diferencia del cine colombiano frente a sus similares de otros países latinoamericanos fue el tímido alcance de la iniciativa de hacer cine con ingredientes sexuales en una sociedad bastante mojigata y temeraria.

En los años noventa se genera una gran crisis en la cantidad de películas producidas por año, debido en buena parte al cierre definitivo de FOCINE (la compañía estatal dedicada al fomento de la industria cinematográfica en Colombia). Esta baja en la producción coincidió con la realización de algunas de las mejores películas de la historia del país como La estrategia del caracol (Sergio Cabrera, 1993), La gente de 
la Universal (Felipe Aljure, 1993) y Confesión a Laura (Jaime Osorio, 1990); sin que necesariamente pueda establecerse una relación de causalidad entre ambos fenómenos.

A partir de la puesta en marcha de la nueva ley del cine, la industria del cine en Colombia está experimentando un período de "bonanza" caracterizado por la producción de más de diez películas por año, la mayor asistencia del público colombiano a las salas y un mayor despliegue de los estrenos cinematográficos en la televisión. ${ }^{1}$ Este índice de producción, hablando en términos de industria, sigue siendo de todas formas bastante irrisorio comparado con países de la región como Brasil, México y Argentina y los índices de taquilla son completamente insuficientes toda vez que, por ejemplo, las películas colombianas más taquilleras de la historia escasamente alcanzan un poco más de un millón de espectadores y desde 1996 (año de despegue de esta industria) sólo 19 películas alcanzaron la mínima suma de 200 mil espectadores. Es relevante mirar que el año 2006, el más exitoso hasta el momento para las películas colombianas, reportó una taquilla para el cine nacional de dos millones ochocientos siete mil espectadores de un total de más de veinte millones de espectadores, constituyendo sólo el 13,88\%. ${ }^{2} \quad$ En el mismo período hay casos dramáticos, como los de 1997 y 1999, en donde la taquilla para el cine nacional no llegó a constituir el $1 \%$ del total; situación que no obstante había sido la constante antes de 1990, aunque no hay muchos datos al respecto.

Frente a la situación de los últimos años hay mucho optimismo y, ciertamente, se está generando poco a poco industria cinematográfica en Colombia, aunque hay que ser realistas al afirmar que sólo hemos cambiado los pañales para entrar en una primera infancia del cine colombiano.

\section{Sobre la investigación del cine colombiano}

Es importante aclarar, primero que todo, que la información que se presentará a continuación no constituye, ni mucho menos, un estado de la cuestión en investigación sobre cine en Colombia; si no más bien una descripción de algunos de los trabajos que se han hecho relacionados con este tema, atravesados, obviamente, por las políticas estatales de apoyo y fomento a la investigación. Es necesario que se evidencie más bien la necesidad de realizar un estudio de estas características que no sólo identifique cuáles y cuantos trabajos se han hecho para pasar a enunciar los resultados y métodos que se han utilizado para abordar este objeto de estudio, así como las principales temáticas estudiadas para evitar la repetición de trabajos muy similares, que no tienen en cuenta sus antecedentes directos.

La investigación sobre cine en Colombia ha sido escasa pero menos de lo que los académicos pensamos y en los últimos años han surgido interesantes iniciativas para compilar lo que se ha avanzado en esta vía. Es frustrante descubrir que se ha vuelto casi un lugar común en los Estados del Arte de proyectos de investigación afirmar que "en

\footnotetext{
${ }^{1}$ Esto es generado fundamentalmente por el reciente apoyo que los canales privados de televisión están dando a las películas colombianos. RCN, por ejemplo, creó una división que se llama RCN Cine y que se dedica a invertir en la producción ejecutiva de películas. Esta situación ha sido benéfica para el cine en términos de mercadeo y fomento; aunque no ha sido tan beneficiosa para la narrativa de las películas, que se ha visto afectada por una estética y una dramaturgia bastante televisiva

2 Datos de la Fundación Proimágenes en Movimiento, que administra el Fondo de Desarrollo Cinematográfico de la Ley de Cine en Colombia. Sólo incluye estadísticas consolidadas hasta 2007.
} 
Colombia no se ha hecho nada en investigación audiovisual”3. Es importante aclarar que la responsabilidad de esta falta de conocimiento sobre lo realizado en investigación no es responsabilidad únicamente de los investigadores, si no también de mayores esfuerzos de catalogación del material en el país y de una mayor proyección de los resultados de las investigaciones que pueda verse materializado en la producción de libros y artículos.

En los últimos años han surgido algunas buenas e importantes iniciativas para fomentar la investigación audiovisual y dar a conocer lo que al respecto se ha hecho.

En el fomento de la investigación sobre cine en Colombia es importante reconocer el esfuerzo que el Ministerio de Cultura ha hecho, mediante el Fondo de Desarrollo Cinematográfico, con la inclusión de un premio para investigación en temáticas cinematográficas. De igual manera la Alcaldía de Bogotá, a través de la Fundación Gilberto Alzate Avendaño y la Cinemateca Distrital, promueve la investigación audiovisual con una categoría del Programa Distrital de Estímulos (aunque en este caso la investigación sobre cine compite con la que se hace en otros ámbitos de lo audiovisual).

En la realización de inventarios sobre el tema han sido muy importantes las labores desarrolladas por instituciones como el Museo Nacional de Colombia, la Cinemateca Distrital de Bogotá y la realización de la XII Cátedra Anual de Historia Ernesto Restrepo Tirado que en 2008 tuvo el tema "Versiones, subversiones y representaciones del cine colombiano. Investigaciones recientes".

De igual forma, es importante considerar la base de datos de Colciencias, que en su plataforma GroupLac permite visualizar los títulos de las investigaciones realizadas en todos los campos del saber en el país. Para el caso que nos ocupa, se hizo una búsqueda minuciosa de las investigaciones sobre cine colombiano realizadas desde las áreas de comunicación y artes.

Reseñas sobre el tema de la investigación en Colombia han sido realizadas también por revistas como Extrabismos y Kinetoscopio. Todas ellas serán base de la información del presente artículo.

Una de las principales dificultades, de todas formas, se presenta con la línea delgada entre crítica e historia en nuestro país, ya que muchos de los más importantes libros de referencia sobre el tema del cine nacional y su historia, no parten de la investigación sino de la crítica o apreciación, lo que reduce un poco su impacto científico.

Además de abordar los principales teóricos internacionales que abordan los temas relacionados con estudios fílmicos y de la imagen; podría decirse que la inmensa mayoría de los estudios cinematográficos en Colombia parten de dos autores que han sido emblemáticos para abordar el tema de la historia del cine en Colombia: Hernando

\footnotetext{
${ }^{3}$ En lo personal, cuando he sido jurado de concursos a nivel local y nacional sobre investigación o he participado en bancas de evaluación de tesis de pregrado y maestría, he podido comprobar que las referencia utilizadas suelen estar basadas en los mismos autores internacionales, algunos cuantos latinoamericanos y sólo en algunos trabajos aparecen un par de autores colombianos. Los proyectos de investigación realizados en el país casi nunca son tenidos en cuenta como antecedentes de futuras investigaciones nacionales sobre temas similares.
} 
Martínez Pardo y Hernando Salcedo Silva. La gran mayoría de los trabajos indagados tienen como referente las obras de estos importantes autores, cuya labor fue fundamental entre los años 70 y finales de los 90 para recopilar los distintos períodos del cine colombiano y entender un poco mejor si se puede hablar de un estilo de cine colombiano, en el sentido estricto de la palabra.

Hernando Martínez Pardo publicó en 1978 su libro Historia del Cine Colombiano ${ }^{4}$, que se constituye en el primer libro que recopila los principales hitos de la historia colombiana hasta el momento y que se ha convertido en el libro de cabecera de quienes se han interesado por trazar diferentes historiografías del cine nacional. Es importante destacar, no obstante, que ya en 1973 el importante crítico de cine francés Georges Sadoul ya había hecho referencia muy someramente al cine colombiano en su libro Historia del Cine Mundial ${ }^{5}$

La obra de Martínez Pardo es la más importante recopilación histórica de hitos en la filmografía nacional y constituye un importante análisis de la trayectoria y evolución de la cinematografía en Colombia, tanto así que no ha surgido aun (más de treinta años después) una obra que actualice o complemente el gran rastreo y análisis que Martínez hizo en este libro.

Hernando Salcedo Silva, por su parte, realizó a inicios de la década de 1980 una interesante recopilación y análisis del cine colombiano del período silente ${ }^{6}$, tomando desde los primeros indicios del cine en el país (dos años después de la invención del cinematógrafo, en 1897), pasando por los primeros largometrajes en la década de 1920, llegando hasta finales de la década de 1940. Su trabajo combina el recuento de anécdotas sobre la actividad cinematográfica en el país con una interesante aproximación a una periodización del cine en Colombia. En esta última línea sobresale su clasificación de los períodos de la crítica en Colombia y su relación con la reseña periodística, la apreciación cinematográfica, la crítica literaria y los estudios académicos.

Una referencia que suele aparecer de manera frecuente también es la del texto Crónicas de cine (1974) de Hernando Valencia Goelkel, uno de los más importantes críticos cinematográficos del país. Su texto no se limita sólo a lo que propone el título si no que también constituye un importante documento sobre el cine del período en el que fue escrito, teniendo en cuenta la importante trayectoria de su autor, quien empezó con esta tarea desde la década de 1950.

Es muy relevante el trabajo de estos autores, pero lamentablemente muchos marcos teóricos de las investigaciones sobre el tema del cine colombiano no van más allá de estas referencias bibliográficas y es evidente que cada nuevo proyecto desconoce buena parte de sus antecedentes directos, lo que ha llevado a que se aborden varias veces los mismos temas sin tener en cuenta las conclusiones de iniciativas análogas. Esta situación ha generado un gran desconocimiento de lo que se investiga desde las

\footnotetext{
${ }^{4}$ Martínez, H (1978). Historia del cine colombiano. Bogotá: Librería y Editorial América Latina.

${ }^{5}$ Sadoul, G (1973). Histoire du Cinema Mondial, des origines a nos jours. París: Flammarion.

${ }^{6}$ En el libro: Salcedo, S (1981). Crónicas del cine colombiano 1897-1950. Bogotá: Carlos Valencia Editores.
} 
instituciones y la sensación más o menos generaliza de que frente al tema de la investigación sobre cine en Colombia "no se ha hecho nada".

Aparte de los libros anteriormente mencionados, es importante considerar otros textos menos difundidos como Reportaje crítico al cine colombiano ${ }^{7}$ de Umberto Valverde con una importante recopilación testimonial de algunas de las más importantes figuras del cine colombiano; El vaivén de las películas colombianas (de 1977 a 1987) ${ }^{8}$ de Mauricio Laurens que hace algunos aportes importantes desde la historiografía del período, pero fundamentalmente desde la crítica. Es importante destacar, igualmente las compilaciones de textos de importantes críticos del país como Luis Alberto Álvarez con su serie de tres libros Páginas de cine, en donde se dedica un capítulo a recopilar algunos de los textos publicados por este autor en el periódico El Colombiano sobre el tema del cine colombiano. Otros libros de compilación muy importantes son: Textos de cine 1977-1982 ${ }^{10}$ de Alberto Ramos y Comunicación, cine colombiano y ciudad ${ }^{11}$ de Oswaldo Osorio. Ambas obras recopilan artículos ya publicados de sus autores y en el segundo caso es muy importante rescatar la intención del autor de dar un enfoque histórico a la selección de algunos de sus artículos para que no se trate solamente de un texto compilatorio. Mención aparte merece también la compilación de los principales artículos de Andrés Caicedo, novelista y crítico de cine caleño, que se ha convertido en autor de culto y que durante los años setenta fue el director de la revista especializada Ojo al cine $e^{12}$ y cuya obra de crítica cinematográfica fue recogida por sus amigos y cineastas Luis Ospina y Sandro Romero.

Desde un punto de vista más temático, es posible encontrar libros como El cine de la violencia ${ }^{13}$ que no constituye un análisis del tema, pero sí es un importante insumo de investigación al presentar la transcripción de los guiones originales de cuatro de las más importantes películas colombianas sobre el tema.

A pesar del incipiente estado, es necesario reconocer que lo que se ha investigado es mucho más de lo que normalmente se conoce. Es necesario, igualmente, reconocer una gran evolución entre los primeros trabajos académicos, muy emparentados con la crítica $\mathrm{y}$ en los que se alternan los datos con las opiniones y las actuales investigaciones, con un mayor rigor científico y metodologías más apropiadas para el estudio de la cinematografía nacional, desde disciplinas tan disímiles como la historia, la sociología, la literatura, la lingüística y la comunicación, entre otras.

A juicio del crítico e historiador colombiano Oswaldo Osorio, podría decirse que "lo que se ha escrito sobre la cinematografía del país, no corresponde siquiera, como sería

\footnotetext{
${ }^{7}$ Valverde, U (1978). Reportaje crítico al cine colombiano. Bogotá: Toronuevo.

${ }^{8}$ Laurens, M (1988). El vaivén de las películas colombianas de 1977 a 1987. Bogotá: Contraloría General de la República.

${ }^{9}$ Alvarez, L. Páginas de Cine. Vol. I (19888), Vol. II (1992). Medellín: Universidad de Antioquia.

${ }^{10}$ Ramos, A (1982) Textos de cine de 1977-1982.

${ }^{11}$ Osorio, O (2005). Comunicación, cine colombiano y ciudad. Medellín: Universidad Pontificia Bolivariana

${ }_{12}^{12}$ Caicedo A (1999). Ojo al cine. Bogotá: Norma. Compilación de Luis Ospina y Sandro Romero Rey

${ }^{13}$ Sánchez, M (1987) El cine de la violencia. Bogotá: Universidad Nacional de Colombia
} 
apenas lógico, a la dinámica lenta y episódica de la producción cinematográfica, sino que su andar ha sido aun mucho más moroso ${ }^{14,}$.

\section{Los intereses investigativos}

Es claro, de todas formas, que ahora hay un interés renovado hacia la investigación relacionada con el cine nacional que se ha visto avivada por el creciente interés hacia la producción cinematográfica en Colombia y por el aumento de profesionales colombianos cursando estudios de Maestría y Doctorado en este campo en universidades, fundamentalmente extranjeras. Según Pedro Adrián Zuluaga "Si en los años sesenta la práctica del cine en Colombia se vio sacudida por el regreso al país de directores formados en el exterior, algo va a ocurrir, o ya está ocurriendo, en el terreno de los estudios sobre el audiovisual" $"$.

Al hacer una revisión de los títulos de las investigaciones que han sido inventariadas en las recopilaciones anteriormente mencionadas, podemos encontrar fundamentalmente un gran interés por los temas de:

Períodos del cine colombiano

Relación entre cine e industria en Colombia

La obra de los autores

El documental

La crítica y el cineclubismo

Períodos del cine colombiano: Tal vez el período que ha sido más estudiado en la historia del cine colombiano es el de los pioneros y este abordaje se ha hecho desde disciplinas como la historia, la comunicación y la sociología; lo que evidentemente constituye un cruce de paradigmas interesantes por constituirse, muchas veces, en estudios interdisciplinarios.

A los textos ya mencionados de Laurens (1988), Valencia (1974), Salcedo (1981) y Ramos (1982) se suman algunas otras iniciativas que estudian períodos concretos. Uno de los más abordados es, sin duda, el período de los pioneros del cine; tema de interés de autores como Edda Pilar Duque, quien publicó los libros Veintiun centavos de cine (1988) y La aventura del cine en Medellín 1992). En sus textos, Duque explora los inicios del cine haciendo referencia a la actividad cinematográfica de realización, así como a los esfuerzos de los primeros exhibidores; resaltando entre otras la figura de Camilo Correa, el fundador de la cadena cinematográfica más antigua que aun existe en Colombia, Procinal.

En la misma línea encontramos algunos textos que pretenden ir más allá del almacenamiento de material importante de archivo para proponer análisis del mismo y que son fundamentalmente auspiciados por instituciones culturales o educativas del orden regional o nacional. En este sentido tenemos textos como: 50 años del cine sonoro y parlante en Colombia: Archivo histórico cinematográfico colombiano de los Acevedo (1987) y Tiempos del Olympia (Nieto y Rojas, 1992) financiados por la Fundación Patrimonio Fúlmico Colombiano; El gran Olympia: vida, pasión y muerte (Atehortúa, 1999) del Fondo Mixto de Cultura de Manizales; Miradas esquivas a una nación fragmentada (López, 2006) auspiciado por el Instituto Distrital de Cultura y

\footnotetext{
${ }^{14}$ Cuadernos de cine colombiano, investigación e historiografía \# 13 nueva etapa. Cinemateca Distrital de Bogotá, 2008 p. 6

${ }^{15}$ Ibid, p. 4 
Turismo de Bogotá y el texto La memoria visual de la narrativa colombiana en el cine (Cadavid, 2006) editado por la Universidad de Antioquia, entre otros.

Sobre el período del sobreprecio (años 70) aparecen también algunos libros en los que se analizan los productos audiovisuales realizados al amparo de la política de FOCINE como El cortometraje del sobreprecio datos 1970-1980 (1982) editado por la Cinemateca Distrital y Los mediometrajes de FOCINE (Restrepo, 1989)

Sobre el cine de los años ochenta se pueden encontrar menos trabajos de investigación y entre ellos es interesante señalar El cine de Gustavo Nieto Roa, una vida de película (Nieto, 1997) que en clave de autobiografía señala un tipo de cine a menudo despreciado en el país, el cine popular y comercial, cuyo principal representante es el autor del libro y cuyos alcances son tan relevantes que se habla, a menudo de forma peyorativo del nietorroismo para referirse al cine cómico colombiano dirigido al gran público.

De las aproximaciones a esta temática, quizá la más relevante como insumo para los investigadores del tema sea Largometrajes colombianos en cine y video 1915-2004 (2005), una importante compilación que incluye no sólo las referencias a las películas documentales y de ficción de la historia de Colombia si no también sus sinopsis, algunos datos de las producciones y comentarios críticos breves sobre algunas de ellas.

Haciendo un rastreo entre los trabajos realizados desde las universidades, por los grupos de investigación

Relación entre cine e industria en Colombia: Este tema, aunque de menor manera, aparece también reseñado en algunos textos. Algunos libros hacen referencia al tema de legislación sobre cine y entre ellos pueden mencionarse, aparte de los folletos y material de información sobre la ley de cine, al libro Legislación del cine en Colombia (Suárez, 1988) y también puede consultarse el libro Impacto del sector cinematográfico en la economía colombiana: situación actual y perspectivas (2003) del convenio Andrés Bello- Ministerio de Cultura y Proimágenes en Movimiento y el artículo Evocar la vida. Contextos y variaciones en el cine latinoamericano reciente de Germán Rey, basado en una conferencia impartida en el Museo de Bellas Artes de Houston en septiembre de 2003.

A pesar de no existir muchos libros sobre el tema, éste aparece de forma recurrente en las convocatorias de investigación que se realizan sobre el tema del cine y en tesis de grado de programas como comunicación y economía. En este sentido, Luisa Fernanda Acosta (2008: 34) encontró trece monografías relacionadas con este tema en el país. Junto con los proyectos relacionados con la historia del cine colombiano (diecinueve proyectos) se puede decir que se trata de los intereses más comunes entre los trabajos de grado relacionados con el cine colombiano, encontrándose en muchos de ellos una presencia muy fuerte de los temas conflicto, violencia y cine.

Este interés se ve de manera más fuerte en las investigaciones realizadas desde la academia norteamericana en donde podemos encontrar más de doce trabajos relacionados con el tema de la violencia en el cine colombiano y latinoamericano. Los estudios realizados desde las universidades norteamericanas arrojan importantes datos sobre nuestra cinematografía desde una visión externa que a veces es presentada 
sobresalen los trabajos de Suárez (2005 y 2008), Caro (2006 y 2008), Kantaris (2007 y 2008) y López (2000 y 2003).

La obra de los autores: Con respecto a los autores se presenta un gran interés hacia la obra de Víctor Gaviria, con su carácter neorrealista y casi documental, relacionado fuertemente con la violencia urbana contemporánea en el país. Su relevancia histórica, social y cinematográfica ha concentrado la atención de los investigadores y por esta razón podemos encontrar entrevistas y análisis de su filmografía en el libro Víctor Gaviria, los márgenes al centro (Ruffinelli, 2004) que, según el crítico Oswaldo Osorio "es el más completo tratado que se ha hecho sobre el realizador antioqueño, abordando su universo visual, literario, temático y metodológico desde varias perspectivas: la crítica, el análisis, la entrevista y el testimonio de sus colaboradores" (Osorio, 2008).

$\mathrm{Su}$ obra despierta un gran interés en los investigadores que desde las universidades de Estados Unidos analizan el tema del cine colombiano ${ }^{16}$ y es por esto que podemos encontrar los artículos: Imagen y subalternidad: El cine de Víctor Gaviria (DunoGottberg, 2003) publicado en Venezuela, así como dos entrevistas realizadas a Gaviria: Cinematic realism and the restoration of everyday life (2008) y Violencia, representación y voluntad realista (2002). Se destacan igualmente los trabajos La novela picaresca: exploraciones ficcionales de la criminalidad juvenil del narcotráfico, tesis doctoral de Margarita Jácome (2006) y el trabajo de análisis sobre el tema de la condición humana desechable realizado por Jáuregui y Suárez (2002) a partir del análisis de personajes en tres películas colombianas, en donde se exploran temas como la cosificación del individuo y la pérdida de su dignidad humana en el término "desechable". La película Rodrigo D No Futuro de Gaviria es nuevamente objeto de análisis en el capítulo que Wilson publica en el libro Italian Neorrealism and Global Cinema (Wilson, 2007) y en donde el autor hace una comparación entre la obra Umberto D del director neorrealista italiano Vittorio De Sica y la película de Víctor Gaviria.

Sobre el cine de la violencia en Colombia, tocando también el trabajo de Gaviria, Kantaris (2008) publica un artículo sobre cine urbano y violencia en Colombia y Quintero (2007) investiga la obra de Gaviria desde su tesis doctoral de la Wayne State University.

Otros autores que han sido estudiados han sido los relacionados con el tema del documentalismo a quienes haré mención en el siguiente apartado.

El documental: El tema del documental es especialmente importante en Colombia, pues este género cobró especial importancia en los años setenta a partir del interés de los realizadores de denunciar los problemas sociales del país y de hacer una labor de apoyo comunitario importante.

El documentalismo de los setenta está caracterizado, como ya se había mencionado, por las tendencias políticas de izquierda y una posición prácticamente militante al pie de las comunidades afectadas por los problemas sociales en Colombia.

Es importante anotar que, a diferencia del largometraje, la producción del documental no está centralizada en Colombia. Las más importantes escuelas de documentalistas del

\footnotetext{
${ }^{16}$ Los datos sobre las investigaciones norteamericanas están tomados del artículo La academia estadounidense y el cine colombiano. Miradas desde el Norte de Juan Suárez.
} 
país han surgido en Cali en los años setenta y Medellín en los años ochenta. Importantes iniciativas han surgido también con proyectos de la costa caribe colombiana y, por supuesto, desde Bogotá. El desarrollo del documental en los últimos años se ha visto también fortalecido por la aparición de escuelas de cine como la de la Universidad Nacional sede Bogotá y el impulso dado por la escuela de documentalistas de Cali que ha crecido al amparo de la Escuela de Comunicación Social de la Universidad del Valle.

El género ha sido impulsado también desde la televisión regional y nacional y en este sentido se destacan proyectos de series documentales como Yuruparí( promovido por Audiovisuales, la empresa de capital estatal, en los años ochenta), Rostros y rastros de la Universidad del Valle de Cali y Muchachos a lo bien de la Corporación Región y la Fundación Social en Medellín. Estos proyectos, entre otros, no sólo han tenido un gran impacto en el impulso del género documental, si no también en el registro de la historia y las historias del país y sus regiones.

En este orden de ideas, la investigación sobre documental también tiene una gran relevancia y es uno de los temas que han sido explorados con mayor interés por los proyectos de investigación en el país.

Entre estos trabajos podemos encontrar libros como Documental colombiano: temáticas y discursos (Gutiérrez y Aguilera, 2002) y más de una decena de tesis de grado relacionadas con el tema. Cabe resaltar que, desde los grupos de investigación registrados en Colciencias hay varios proyectos relacionados con la temática del documental, aunque muy probablemente este número es mayor del que aparece registrado.

La crítica y el cineclubismo: Los críticos y los cineclubistas en Colombia no se han limitado a su labor del día a día y, dada la gran importancia de ambos movimientos en el país, han publicado también algunos trabajos sobre su oficio, la trascendencia y limitaciones que tiene su ejercicio en un país como Colombia, con grandes problemas de política y gestión cultural.

Se destacan aquí las memorias de los encuentros de críticos de cine en Pereira como Nido de Cóndores (Ossa, 1999); el texto Sobre relatos, cuentos y ensayos de cineclubes, promovido por la Asociación Nacional de Cineclubes (Colmenares, 2003) y los libros Ser o no ser crítico de cine (Posada, 1996) y Apuntes para un periodismo cinematográfico (Restrepo, 1997).

\section{La investigación académica}

Al panorama anterior podemos añadir los proyectos financiados por las universidades del país y que aparece marginado de muchas de las compilaciones por su escasa visibilidad y poco impacto, traducido en la limitada cantidad de libros y artículos disponibles para su búsqueda.

Colciencias, el principal ente impulsor del Estado Colombiano para el fomento de la ciencia en el país cuenta con un software de registro de la producción de los grupos de investigación llamado GroupLac. En el GroupLac se agrupan los investigadores, 
proyectos, productos y grupos de investigación por áreas del conocimiento $\mathrm{y}$ universidades. Si bien, aparece el registro de los títulos de las investigaciones, sólo se menciona que se han hecho o se hicieron pero no hay más referencias a estos estudios por lo que cabe suponer que estarán archivos en los anaqueles de las universidades con un número limitado de consultas.

A esta situación hay que sumar el hecho de que Colciencias Colombia tiene muy poco en cuenta el fomento de la investigación realizada desde las ciencias sociales o desde las artes, pues su apoyo se canaliza fundamentalmente hacia la innovación tecnológica, la experimentación de las llamadas ciencias duras y la coyuntura relacionada con problemas neurálgicos del país en lo que ellos han llamado los frentes estratégicos. La comunicación, obviamente, es una gran ausente en este panorama y el cine es poco menos que inexistente.

El software de registro de proyectos de investigación, Group Lac, clasifica los grupos de investigación por áreas del conocimiento e instituciones y los categoriza en A, B y C, de acuerdo a su experiencia y producción intelectual.

En una revisión al software GroupLac, sin hacer una comprobación exhaustiva de la existencia de los resultados publicados de las investigaciones, podemos encontrar proyectos relacionados con el tema que han sido abordados desde las facultades de artes, comunicación y ciencias sociales.

Para buscar lo investigado en el área de cine, realizamos una búsqueda de los grupos de investigación que se relacionan con comunicación, sociología, historia y artes visuales para una revisión de un total de 445 grupos de investigación.

En Comunicación hay 95 grupos registrados en Colciencias, de los cuales sólo 26 son reconocidos y categorizados por Colciencias en categorías $\mathrm{A}, \mathrm{B}$ y $\mathrm{C}$, de acuerdo a su nivel de experiencia y producción intelectual. De los 95 grupos, sólo cinco tienen algún nivel de producción relacionada con el tema del estudio del cine desde alguna perspectiva, aunque más de diez declaran en sus líneas al cine como objeto de estudio.

El grupo de investigación en Comunicación, cultura y ciudadanía colombiana de la Universidad Nacional de Colombia reporta una línea de investigación en historia del cine colombiano en los años setenta y dos productos relacionados con el tema del cine, aunque curiosamente ninguno de ellos con relación a la década de 1970. Los productos son un artículo publicado en la revista Signo y Pensamiento (Acosta, 1999) y un libro publicado por Goliardos (Mora, 1999).

En la Universidad Javeriana de Bogotá se encuentra el grupo Comunicación, Medios y Cultura que tiene una línea de investigación en cultura y narrativas mediáticas y de la que se derivan las investigaciones La narración en el cine colombiano de ficción 19502000 de Gabriel Alba y Maritza Ceballos (2002) y los artículos Glauber Rocha: una estética (politca) del cine (Arias, 2007), Cine y vida cotidiana en la Bogotá de los años veinte (Arias, 2007-2). La ponencia El discurso nacionalista en el cine colombiano 2005-2006 presentada en la XII Cátedra Anual de Historia Ernesto Restrepo Tirado en 2008.

De igual forma, se destaca el trabajo Puesta en escena de las pasiones en el cine. Tesis de doctorado.; 1998 - 2005, tesis doctoral de Maritza Ceballos de la Universidad 
Autónoma de Barcelona, publicada en TDX (Theses and Dissertations Online) en 2006 y del que se desprenden los artículos Las pasiones: interacción y retórica publicado en la revista Signo y Pensamiento Vol. 25 (Ceballos, 2006) y el texto Historias y argumentos. 50 años de hibridación narrativa (Ceballos, 2006-2).

En la Universidad de La Sabana, se destaca el trabajo del grupo de investigación Observatorio de Medios que declara una línea enfocada en cultura de masas e industrias culturales con un proyecto de investigación denominado "Narrativas del conflicto armado en el cine colombiano", desarrollado por Sandra Ruiz Moreno y Jerónimo Rivera Betancur entre 2007 y 2009. En la producción académica del grupo se destacan, igualmente, los artículos Conflicto armado y cine colombiano en los dos últimos gobiernos (Ruiz et al, 2007), Personajes del cine colombiano (Rivera, 2007), El auge del cine colombiano (Rivera, 2007-2) y El cine como golosina (Rivera, 2008).

En la ciudad de Medellín se destaca el trabajo del grupo de investigación IMAGO con el desarrollo de dos proyectos relacionados con el cine. En el primero se realizó una búsqueda de los hábitos y preferencias de consumo de los estudiantes de primer semestre de comunicación con relación al cine y el aporte del mismo a sus competencias previas al ingreso a la universidad ${ }^{17}$ y el segundo fue sobre los personajes, las acciones y los escenarios del cine colombiano entre 1990 y $2005^{18}$.

De los proyectos mencionados salieron ponencias para certámenes como el Encuentro de la Federación Latinoamericana de Facultades de Comunicación (Felafacs, Bogotá 2006), Festival de Cine Feria de las Flores de Medellín, las VII Jornadas de Investigación de la Universidad de Medellín y Comunicación $10^{19}$ en Murcia (España).

Se destacan los artículos Estudiantes de comunicación, consumidores de cine (Rivera, Osorio y Sánchez, 2006), Imágenes y sonidos desechables (Rivera, Osorio y Sánchez, 2006-2), Una mirada a los villanos en el cine colombiano de 1990 al 2005 (Lopera, 2007), El cine: realidad fragmentada o ficción de continuidad (Correa, 2002) y Un cine de anécdotas (Vélez, 2007) y El pacto ficcional en la realidad local (López, 2005).

De igual forma aparece el libro Narrativas Audiovisuales: Personajes, acciones y escenarios (Correa et al, 2008) editado por el Sello Editorial de la Universidad de Medellín y publicado en 2008 con la participación de grupos de investigación de Colombia, Argentina y España y que fue publicado como resultado de las VIII Jornadas de Investigación de la Universidad de Medellín.

En la misma Universidad de Medellín se encuentra el grupo Comunicación e Identidad que realizó un proyecto de investigación relacionado con el tema del cine: La representación de las identidades de Medellín en el documental sobre la ciudad entre 1994 y 2005.

\footnotetext{
17 Proyecto de investigación "Consumo de cine en estudiantes de comunicación de Medellín". Investigadores: Jerónimo Rivera, Uriel Sánchez y Jhon Jaime Osorio. Universidad de Medellín 2005.

18 Proyecto de investigación "Personajes, acciones y escenarios en el cine colombiano de 1990-2005". Investigadores principales: Ernesto Correa y Jerónimo Rivera. Universidad de Medellín 2007.

${ }^{19}$ Evento conmemorativo de los diez años de la Facultad de Comunicación de la Universidad Católica de San Antonio de Murcia, septiembre de 2007, Murcia (España).
} 
Derivado de esta investigación y de otros trabajos del grupo, se destacan el artículo Cine colombiano: Identidad e industria. Un acercamiento desde la creación audiovisual en la universidad (López C, 2008) y el texto El documental como representación de la ciudad (López A, 2008), capítulo del libro resultado de las Jornadas de investigación de la Universidad de Medelín.

El centro de investigaciones de la comunicación de la Universidad de Manizales presenta los proyectos Tropología del Cine. Metáfora, metonimia, alegoría y símbolo en el cine de autor; 2008Trabajo de analisis poéito y retórico de tropos al interior del cine de autor contemporáneo y Mitos y arquetipos en el cine contemporáneo occidental; 2007 y presenta entre su producción algunos artículos escritos por Carlos Fernando Alvarado para el periódico estudiantil Página, que por sus títulos podrían ser críticas o reseñas cinematográficas más que textos de invetigación propiamente dichos.

Desde los grupos de investigación en sociología no se encontró ningún proyecto de investigación relacionado con cine.

De los grupos de investigación en historia encontramos uno que relaciona la historia con fuentes audiovisuales, proveniente de la Universidad Nacional de Colombia, sede Medellín. Este grupo sólo presenta la tutoría a un trabajo de grado sobre neorrealismo italiano y un proyecto planteado de crear una base de consulta de materiales audiovisuales y bibliografía teórica sobre imagen, cine y video para estructurar una línea de investigación en historia y cine. Sin embargo, no se explicita en que estado está este proyecto que tiene como fecha 2006.

Llama la atención que, a pesar de que existen grupos con temáticas que podrían ser estudiadas desde el cine, como identidad y memoria cultural; no encontramos registrados proyectos de investigación relacionados con el tema de cine e historia.

Finalmente, queda la sensación de que en el área de las artes hay un gran subregistro, pues de 145 grupos declarados a Colciencias, sólo aparecen reconocidos y con información actualizada 16 grupos. Algunos nombres de los grupos sugieren interés hacia el tema del cine y de la investigación audiovisual, pero no es posible conocer los datos de la producción académica al respecto. También es importante, de todas formas, reconocer que el formato establecido por Colciencias privilegia la producción científica y muchos de los grupos de investigación de esta área mezclan la producción con el trabajo de creación artística, por lo que seguramente no aparecen fortalecidos a la luz de la medición que de ellos se hace. Al respecto, los investigadores de esta área se han quejado en varios escenarios académicos en donde ha hecho presencia Colciencias.

Sin embargo, hay que reconocer la existencia de algunos trabajos desde el área de las artes. En primera instancia, el grupo de investigación Reflexiones en torno a la producción de material audiovisual de la Universidad Manuela Beltrán de Bogotá presenta tres proyectos de investigación sobre producción audiovisual que tienen productos relacionados con el tema del cine, entre los que se encuentran las ponencias Escenarios pintados para el cine expresionista presentada por Ricardo Guerra en el seminario

Hágase la luz: un recorrido por la historia de la dirección de fotografía cinematografica en 2008 y El uso del cine y el audiovisual como fuente para la investigacion histórica 
presentada por Juana Rubio en el Festival Audiovisual del Cerro de Guadalupe el mismo año. Así mismo, presentan algunos proyectos de grado relacionados con el tema del cine.

Aparecen, igualmente, grupos con nombres y líneas de investigación muy interesante, pero ninguna información sobre proyectos. Es el caso de los grupos Documental Colombia y Kinos, movimiento perpetuo de la Universidad Nacional. Este último sólo menciona la realización de una investigación en 2006 sobre tecnología cinematográfica. Esta situación también se presenta con el grupo de investigación Historia del cine colombiano de la Corporación Universitaria Nueva Colombia, que no tiene ninguna información registrada.

El grupo de investigación Estudios de la imagen de la Universidad Jorge Tadeo Lozano de Bogotá presenta la investigación La animación en Colombia; 2007 - 2008 que no presenta ningún resultado asociado que haya sido publicado.

\section{Las agremiaciones de investigadores}

Si la investigación en el tema de lo audiovisual y, particularmente, en el tema del cine es incipiente; mucho más lo es la intención de los investigadores por validar estudios análogos o compartir información y conocimiento con colegas pares de otras universidades del país. En este sentido, es importante resaltar los esfuerzos (la mayoría de ellos aislados) de algunos grupos de investigadores que han intentado hacer comunidad científica alrededor del tema de la investigación en comunicación.

En primera instancia, es importante mencionar a Redicom, una asociación de investigadores de la comunicación convocada desde la Pontificia Universidad Javeriana. Su objetivo principal es fortalecer el campo académico de la comunicación a través de la investigación, el desarrollo y la gestión del conocimiento, mediante la producción y circulación del conocimiento en comunicación y cultura a través del intercambio permanente de proyectos y productos de investigación de los diferentes investigadores y grupos, el intercambio y circulación de publicaciones, la creación de foros de discusión sobre temas relacionados con políticas de comunicación y cultura, la realización de proyectos de investigación conjunta y la promoción y realización de eventos $\mathrm{y}$ eventuales programas académicos.

En el ámbito iberoamericano, es importante resaltar la labor de la Red Iberoamericana de Investigación en Narrativas Audiovisuales (Red INAV). que desde 2005 se dedica a propiciar el intercambio académico e investigativo entre profesionales de la comunicación de Iberoamérica con un interés común en el estudio de las narrativas audiovisuales. Entre sus principales objetivos busca aumentar la presencia del estudio de las narrativas audiovisuales en los certámenes de comunicación e investigación en Iberoamérica, fomentar el desarrollo de investigaciones en los países Iberoamericanos y generar matrices metodológicas comunes mediante la discusión sobre metodologías de la investigación en narrativas audiovisuales.

La Red, en la que participan activamente los integrantes del grupo de investigación ADMIRA de la Universidad de Sevilla, es dirigida por Jerónimo Rivera Betancur de la Universidad de La Sabana (Colombia) y cuenta con 79 investigadores provenientes de España, EEUU, México, Puerto Rico, Colombia, Ecuador, Brasil, Argentina y Chile. 


\section{Conclusiones}

La conclusión a la que puede llegarse es que, definitivamente, es mucho lo que falta por hacer pero el camino ya ha empezado a recorrerse. Es claro, de todas formas, que los esfuerzos no han sido pocos pero han estado muy dispersos. La primera labor debe ser, en el espíritu de este artículo, la clasificación y categorización de las investigaciones realizadas en Colombia sobre los distintos aspectos relacionados con el cine desde los distintos sectores involucrados en el tema: entidades estatales y académicas e investigadores independientes. Esta revisión no debe, por supuesto, dejar de lado los proyectos realizados en otros países (fundamentalmente en Estados Unidos) por investigadores interesados en el cine colombiano y latinoamericano.

De todas formas, hay que reconocer que probablemente este panorama sea sólo un espejismo, pues conocemos los títulos de proyectos de investigación, artículos y libros pero no tenemos mucha información del contenido de los mismos. De igual manera, es muy posible que existan muchos proyectos más que no hayan sido revisados, debido a que sólo se conocen en la institución que los auspició.

Es muy importante que después de unir esfuerzos, los investigadores del tema se pongan de acuerdo en algunas líneas de investigación que permitan desarrollar este campo de estudio y ejerzan presión sobre el apoyo y las políticas de fomento a la investigación que desde el Estado aun son muy insuficientes.

Para terminar, quiero hacer énfasis en las palabras de Pedro Adrián Zuluaga, destacado crítico de cine colombiano "Esta ola de académicos es la llamada a producir un conocimiento nuevo sobre un cine como el colombiano que siempre ha estado ahí, como un dragón que espera ser despertado" (Zuluaga, 2008:4).

\section{REFERENCIAS BIBLIOGRÁFICAS}

- Acosta, L (2008). De aficionados a cibernautas en Cuadernos de cine colombiano 13.2008 nueva etapa. Bogotá: Cinemateca Distrital.

- $\quad$ (1999). El cine que mira a Bogotá: una panorámica para comenzar. Revista Signo Y Pensamiento No. 35

- Álvarez, L A (1988). Páginas de cine vol. 1. Medellín: Universidad de Antioquia.

$\bullet$ (1992) Páginas de cine vol. 2. Medellín: Universidad de Antioquia

Antioquia

(1998) Páginas de cine vol. 3. Medellín: Universidad de

- Arias, J (2007). Glauber Rocha: una estética (politca) del cine en Revista Arte Facto. Bogotá: Universidad Nacional de Colombia.

- $\quad$ (2007-2) Cine y vida cotidiana en la Bogotá de los años veinte en Cuadernos Hispanoamericanos: Revista Mensual De Cultura Hispanica.

- Atehortúa, A (1999). El gran Olympia: Vida, pasión y muerte. Manizales: Fondo Mixto de la Cultura de Caldas.

- Cadavid, A (2006). La memoria visual de la narrativa colombiana en el cine. Medellín: Universidad de Antioquia. 
- Caicedo A (1999). Ojo al cine. Bogotá: Norma. Compilación de Luis Ospina y Sandro Romero Rey.

- Caro, E (2006). Continuidad y ruptura: los nuevos paisajes sociofílmicos colombianos. Arizona: Arizona State University.

$\bullet$ (2008). And Medellin exits the closet: Postmodern urban stories. Latin American Urban Cultural Production, Hispanic Issues on line.

- Ceballos, M (2006) Las pasiones: interacción y retórica, en Revista Signo y Pensamiento Vol. 25, No. 49. Bogotá: Universidad Javeriana, (2006-2) Historias y argumentos. 50 años de hibridación narrativa en http://www.javeriana.edu.co/redicom/documents/.

- Cinemateca Distrital (1982). El cortometraje del sobreprecio (datos de 19701980). Bogotá: Cinemateca Distrital.

- Colmenares, M (2003). Sobre relatos, cuentos y ensayos de cineclubes. Bogotá: Universidad Nacional de Colombia.

- Correa, E; Rivera, J; Caminos, J; Ruiz, M (2008). Narrativas audiovisuales: Personajes, acciones y escenarios. Medellín: Universidad de Medellín.

- Correa, E (2002). El cine: realidad fragmentada o ficción de continuidad en Revista Anagramas, Vol. 1 \# 1. Medellín: Universidad de Medellín.

- Convenio Andrés Bello/ Ministerio de Cultura/ Proimágenes en Movimiento (2003). Impacto del sector cinematográfico en la economía colombiana: situación actual y perspectivas. Bogotá: Convenio Andrés Bello/ Ministerio de Cultura/ Proimágenes en Movimiento.

- Duque, E (1988). Veintiun centavos de cine. Medellín: Autores antioqueños.

- $\quad$ (1992). La aventura del cine en Medellín. Bogotá: Universidad Nacional de Colombia/El Áncora Editores.

- Dunno Gottberg, L (2003). Imagen y Subalternidad: El cine de Victor Gaviria en Objeto Visual. Cuadernos de Investigación de la Cinemateca Nacional de Venezuela.

- Focine (1988). Focine 10 años. Nuestra memoria visual. Bogotá: Focine.

- Fundación Patrimonio Fílmico Colombiano (2005). Largometrajes colombianos en cine $y$ video 1915-2004. Bogotá: Fundación Patrimonio Fílmico Colombiano.

- Gaviria, V (2008). Cinematic realism and the restoration of everyday life en Arizona Journal of Hispanic Popular Culture \# 12.

- (2002). Violencia, representación y voluntad realista entrevista con Carlos Jáuregui en Espacio urbano, comunicación y violencia en América Latina.

- González, L y Nieto, J (1987). 50 años del cine sonoro y parlante en Colombia. Archivo histórico cinematográfico colombiano de los Acevedo. Bogotá: Fundación Patrimonio Fílmico Colombiano.

- Jacome, M (2006). La novela picaresca: exploraciones ficcionales de la criminalidad juvenil del narcotráfico, tesis doctoral, Universidad de Iowa.

- Jáuregui, C y Suárez, J (2002). Profilaxis, traducción y ética: La humanidad desechable en "Rodrigo D No futuro", "La vendedora de rosas" y "La virgen de los sicarios". Revista Iberoamericana \# 199.

- Kats, J (2006). Tecnologías de la información y la comunicación e industrias culturales. Cepal Naciones Unidas.

- Kantaris, G (2008). El cine urbano y la tercera violencia colombiana. Revista Iberoamericana \# 223 vol. 74. 


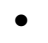

(2007). Soapsudes and histrionics: Media, history and nation in "Bolivar soy yo" en Contemporary Latin American Cinema: Breaking into the Global Market. Lanham, Rowman \& Littlefield.

- Laurens, M (1988). El vaivén de las películas colombianas (de 1977 a 1987). Bogotá: Contraloría General de la República.

- Lopera, A (2007). Una mirada a los villanos en el cine colombiano de 19902005 en Anagramas Vol. 5, No 10. Medellín: Universidad de Medellín.

- López, A (2008). El Documental como representación de la ciudad en Comunicación Pública, Organizacional y Ciudadana-Comunicación e Identidad. Medellín: Universidad de Medellín.

- López, C (2005). El pacto ficcional en la realidad local en Revista Politécnica Vol. 2 No. 1, México.

- (2008). Cine colombiano: Identidad e industria. Un acercamiento desde la creación audiovisual en la Universidad, Medellín.

- Martínez Pardo, H (1978). Historia del cine colombiano. Bogotá: Librería y Editorial América Latina.

- Mora, C (1999). La llegada del cine sonoro a Colombia: Ducrane Films 19371955. Bogotá: Goliardos.

- Nieto, J y Rojas D (1992). Tiempos del Olympia. Bogotá: Fundación Patrimonio Fílmico Colombiano.

- Nieto Roa, G (1997). El cine de Gustavo Nieto Roa. Una vida de película.

- Osorio, O (2005). Comunicación, cine colombiano y ciudad. Medellín: Universidad Pontificia Bolivariana

- (2008). La saga atrasada de un cine que camina lento en Cuadernos de Cine Colombiano 12.2008 nueva etapa. Bogotá: Cinemateca Distrital.

- Ossa, G (1999). Nido de cóndores. Críticos de cine en Pereira. Memorias del IV Encuentro. Pereira: Papiro.

- Posada, G (1996). Ser o no ser crítico de cine. Pereira: Fondo Mixto de la Cultura y las Artes de Risaralda.

- Quintero, L (2007). New disorders of the gaze: Abjection, alterity and agency in the work of Víctor Gaviria. Disertación Doctoral en Wayne State University.

- Ramos, A (1982). Textos de cine 1977-1982. Cali: Gobernación del Valle.

- Restrepo, G (1997). Apuntes para un periodismo cinematográfico. Barranquilla: Instituto Distrital de Cultura.

- Rivera, J; Osorio, J; Sánchez, U (2006). Estudiantes de comunicación, consumidores de cine en Revista Unisinos v. I, $\mathrm{n}^{\circ} 3$, Sao Leopoldo: Unisinos.

- (2006-2). Imágenes y sonidos desechables en Anagramas Vol. 4, No 8. Medellín: Universidad de Medellín.

- Rivera, J (2008). El cine como golosina en Revista Palabra Clave Vol. 11 \# 2. Bogotá: Universidad de La Sabana.

- $\quad$ (2007) Personajes con sello colombiano en Revista Anagramas vol. 11 \# 6, Medellín: Universidad de Medellín.

- $\quad(2007,2)$ El cine colombiano que queremos: un panorama rápido al 2006 cinematográfico en La Revista del Guión Actualidad, Barcelona: Universidad Autónoma de Barcelona.

- (2006) ¿El auge del cine colombiano? en La Revista del Guión Actualidad, Barcelona: Universidad Autónoma de Barcelona.

- Ruffinelli, J (2002). Víctor Gaviria, los márgenes al centr. Madrid: Turner. 
- Ruiz, S; Escallón, C; Niño, D; Romero, A; Rueda, M (2007) Conflicto armado y cine colombiano en los dos últimos gobiernos en Revista Palabra Clave Vol. 10 \# 2. Bogotá: Universidad de La Sabana.

- Sadoul, G (1973). Histoire du Cinema Mondial, des origines a nos jours. París: Flammarion.

- Salcedo Silva, H (1981). Crónicas del cine colombiano 1897-1950. Bogotá: Carlos Valencia Editores.

- Sánchez, I (1987). El cine de la violencia. Bogotá: Universidad Nacional de Colombia.

- Suárez, J (2005). Prácticas de solidaridad: los documentales de Marta Rodríguez. Chicana/Latina Studies 5.1.

- (2008). Decentering the "centro": Noir representations and the metamorphosis of Bogotá. Latin American Urban Cultural Production. Hispanic Issues on Line 3.3.

- $\quad$ (2008, 2) La academia estadounidense y el cine colombiano. Miradas desde el Norte en Cuadernos de cine colombiano 13.2008 nueva etapa. Bogotá: Cinemateca Distrital

- Suárez, M (1988). Legislación del cine en Colombia. Bogotá: Universidad Javeriana.

- Valencia Goelkel, H (1974). Crónicas de cine. Bogotá: Cinemateca Distrital.

- Valverde, U (1978). Reportaje crítico al cine colombiano. Bogotá: Toronuevo.

- Vélez, JM (2007). Un cine de anécdotas en Revista Anagramas vol. 11 \# 6, Universidad de Medellín.

- Wilson, K (2007). From Pensioner to teenager: Everyday violence in De Sica's Umberto D and Gaviria's Rodrigo D: No Future en Italian Neorrealism and Global Cinema. Detroit: Wayne State University Press. 